\title{
Energy Absorption Characteristics of Foam Filled Tri Circular Tube under Bending Loads
}

\author{
Fauzan Djamaluddin \\ Departement of Mechanical Engineering, Engineering Faculty, Universitas Hasanuddin, Gowa \\ Indonesia
}

Received: February 8, 2021. Revised: August 17, 2021. Accepted: September 6, 2021. Published: September 9, 2021.

\begin{abstract}
In this study, the researcher carried out a comparative investigation of the crashworthy features of different tubular structures with a quasi-static three bending point, like the foam-filled two and tri circular tube structures. Energy absorption capacities and failure modes of different structures are also studied. Furthermore, the general characteristics are investigated and compared for instance the energy absorption, specific energy absorption and energyabsorbing effectiveness for determining the potential structural components that can be used in the field of vehicle engineering. Experimental results indicated that under the bending conditions, the tri foam-filled structures were higher crashworthiness behaviour than the two foam-filled circular structures. Therefore, this study recommended the use of crashworthy structures, such as foam-filled tri circular tubes due to the increased bending resistance and energy-absorbing effectiveness.
\end{abstract}

Keywords-Foam, Tube, Crashworthiness, Bending, Energy Absorption

\section{INTRODUCTION}

In the past few decades, many studies have shown considerable importance in investigating the safety and crashworthiness of the vehicles, especially with regards to the structural response of the thin-walled metallic tubes. These metallic tubes are traditional and efficient in absorbing energy from devices. Therefore, they have been previously used in designing and manufacturing vehicles [1]. In the last two decades, many researchers have studied the axial crushing behaviour of the thinwalled columns for improving energy absorption efficiency [2-5]. Abramowicz [6] presented a detailed study of the thin-walled structures that were used as excellent energy absorbers. In the actual automobile crashes, the thin-walled tubes as energy absorbers not only under pure axial load but also under bending load [7]. In this condition, $90 \%$ of structural failures that occurred took place due to a bending collapse [8]. One can duplicate the axial progressive folding in the laboratory experiments in comparison to the bending load. Hence, the researchers have to carry out a comprehensive analysis of the bending behaviour of the thin-walled structures.

All tubular structures, such as altering the design of the tube's cross section and filling the tubes with lightweight materials were used to enhance the energy absorption capacity. It was noted that when the tubes were filled with either foam or honeycombs, the energy absorption capacity of these tubes was significantly improved [1]. In their studies, Poonaya et al. [10] and Hilditch [11] described the different structures under the bending loads. Keeman [9] studied the bending behaviour of the square and rectangular section of the tubes. Other researcher used a double-cell profile comprising two tubes with similar cross-sectional design, and one tube placed concentrically into another tube [12] [13] . Furthermore the tubes were filled with the aluminium foam, which are used to enhance the energy absorption capacity of the thin-walled tubes. Many researchers studied the characteristic crashworthy features of the empty and foam-filled multi-cell tubes which have undergone an axial crushing. Their results indicated that the multi-cell tubes were more efficient [14-15] than the single cells.

This research conducted many experiments and numerical simulations for investigating the two-point bending behaviour of the foam-filled double tubes [1618]. Djamaluddin et al. [19-22] studied the crashworthy characteristics of similar topological structures under the oblique and axial loading conditions. The foam-filled double tubes showed better crashworthy characteristics, which were attributed to the ratio of the crushing resistance of these tubes and the axial crushing load. Vesenjak et al. [23] concluded that foam filled hollow sphere structures have the highest peak under quasi-static and dynamic three-point bending tests and they have more ductile behavior compare other tubes. Li et al. [24] noted a significant effect of the foam-filled tube topologies on the increased energy absorption.

For understanding the crashworthiness of the structures that are used as energy absorbers, the 
researchers compared the bending behaviour of the different structures [25-28]. Hence, in their study, they have evaluated the crashworthy features of thin-walled tubes with different arrangements that undergo bending. For this purpose, they carried out quasi-static three-point bending experiments for the 4 thin-walled structures. They also compared the SEA, energy absorption capacities and the deformation behaviour of these thinwalled structures. Moreover, they also studied the bending crashworthy characteristics and presented the results for the axial crushing.

Several types of cross sections in this study such as double and tri foam filled structures. The deformation and failure in the structure was determined by experimental methods under bending loads. In addition, performance of tubes is calculated based on the equation related to crashworthiness.

\section{MATERIALS AND METHODS}

In this study, the researchers used the aluminium alloy AA6063 T6 thin-walled tubes having a double circular cross-section and derived the following mechanical properties, i.e., yield strength $=126 \mathrm{MPa}$, Young's modulus $=47 \mathrm{GPa}$, and the Uniaxial tensile rupture strain $=0.07$. For determining the stress-strain curves, they carried out the uniaxial tensile tests for the dog-bone samples. They obtained the test samples from the sidewall of the tubes that were parallel to their extrusion direction. The summary of the tube dimensions has been presented in Table 1. Slight inconsistencies were seen with regards to the mechanical properties of the samples having a varied thickness. This was attributed to the difference in the extruding ratio of the samples during their formation.

The nominal density was $0.45 \mathrm{~g} / \mathrm{cm}^{3}$ and mean cell size of the aluminium foam was $\approx 3 \mathrm{~mm}$. After carrying out the material tests, the researchers estimated the mean mechanical properties, i.e., Young's modulus $=625$ $\mathrm{MPa}$, comprehensive strength $=9.74 \mathrm{MPa}$ and the plateau stress $=8.12 \mathrm{MPa}$. As presented in Figs. 1 and 2, they tested the foam-filled multiwall tubes with a circular cross-section.

Table 1. Dimension of tubes

\begin{tabular}{lcccc}
\hline Tubes & $\begin{array}{c}\text { Outer } \\
\text { tube } \\
(\mathrm{mm})\end{array}$ & $\begin{array}{c}1^{\text {st }} \\
\text { inner } \\
\text { tube } \\
(\mathrm{mm})\end{array}$ & $\begin{array}{c}2^{\text {nd }} \\
\text { inner } \\
\text { tube } \\
(\mathrm{mm})\end{array}$ & $\begin{array}{c}\text { Length } \\
(\mathrm{mm})\end{array}$ \\
\hline $21 \mathrm{CT}$ & 31.75 & 12.7 & - & 105 \\
$22 \mathrm{CT}$ & 31.75 & 19.5 & - & 105 \\
$31 \mathrm{CT}$ & 31.75 & 25.4 & 12.7 & 105 \\
$32 \mathrm{CT}$ & 31.75 & 25.4 & 12.7 & 105 \\
\hline
\end{tabular}
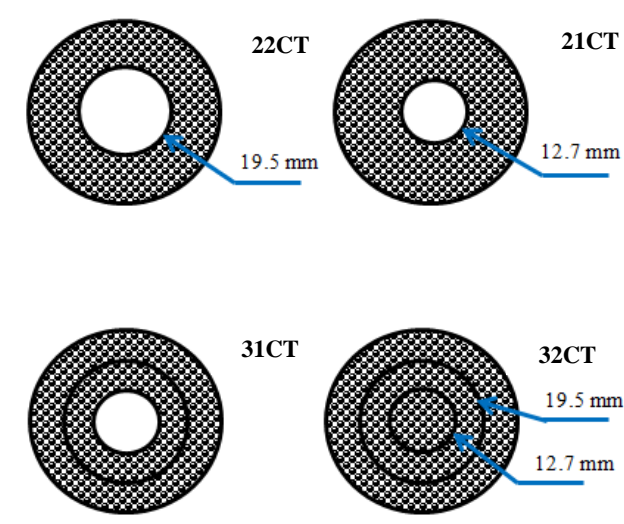

Fig. 1 Cross section of tubes

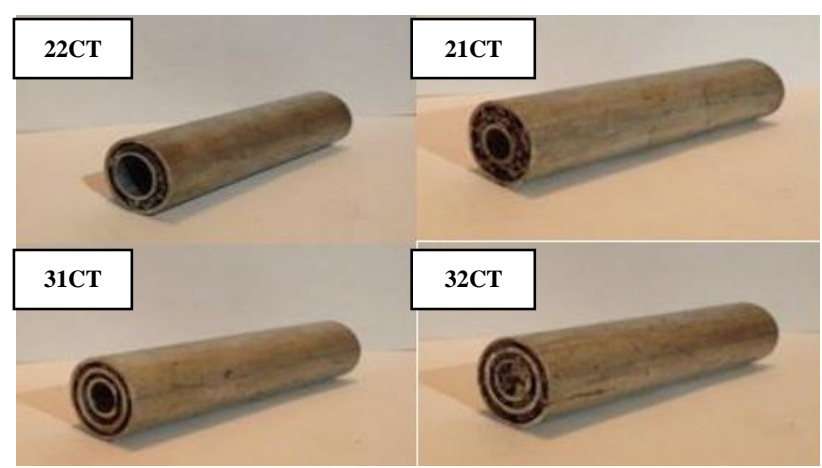

Fig. 2 Types of tubes

Tests were carried out using an MTS810 testing system [29], under displacement control at the steady crosshead speed of $0.2 \mathrm{~mm} / \mathrm{s}$. The specimens and supports were laid on the test bed with the crosshead of the MTS machine placed on a punch. Fig. 3 describes the arrangement and the experimental set-up of all the tests. The diameter of the cylindrical punch and supports was $10 \mathrm{~mm}$. In the case of the outer tubes, the span $L_{o}$ to the diameter ratio (i.e., the side length) was set as 4. For the numerous specimens, the overall length was seen to be $105 \mathrm{~mm}$. Fig. 4 describes the schematic diagram of the three-point bending [24]. Each tube has an identification such as 21CT which means number 2 is a double tube filled with foam, number 1 means a different tube diameter while $\mathrm{CT}$ is a pressure test as listed in table 1.

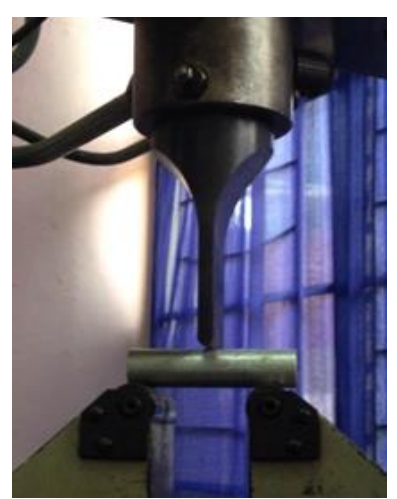

Fig. 3 Three bending point testing 


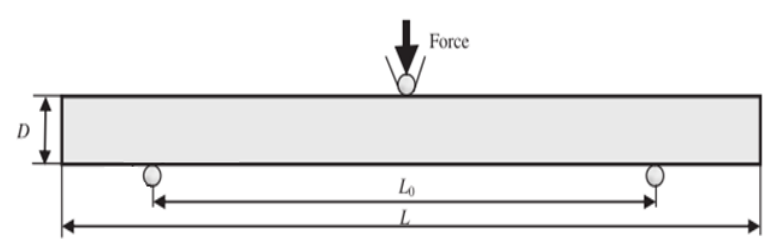

Fig. 4 Schematic of three bending point [24]

\section{RESULTS AND DISCUSSION}

\section{A. Failure Mode}

During the final stage of the bending response of the above circular tubes, the researcher noted an increase in force which was attributed to the contact between the sides of the outer tubing and the wedged punch, if the loading displacement was increased. This effect was not noted in the load-displacement response in the circular structures as the circular tubes underwent a crosssectional ovalisation. Furthermore, the sharp final decrease in the force was associated with the failure and fractures noted in the specimens. When cracks occur, failure mode tests are eliminated with the deflection used to determine the maximal displacement in the test.

Fig. 5 shows the overall photographs of the failed tubes. In a majority of the cases, fractures were noted in the lower regions of the structure which was attributed to the severe tensile stretching. A failure was noted in the structures that were foam filled as they showed numerous cracks. A single crack was noted in the foam-filled two and tri circular tubes, which were propagated in the symmetrically opposite direction as shown in Fig. 6. In comparison to the foam-filled two circular tubes, a different crack failure mode was noted in the foam-filled tri circular tubes, because of a thick inner tube. The crease in the inner tube is delayed due to the influence of the aluminum foam which is formed laterally in the tube wall. Another condition is that the bending process on the tube is hampered due to the increased resistance of the aluminum foam. Bending deformation is also hindered in the structure, on the other hand the tensile stress on the tube wall increases in the double tube and tube tri. With increasing loading causes the outer wall of the tube to break or it is called a failure. In double tube filled with foam, the outer wall breaks larger than the tri tube. (Figures 5 and 6).

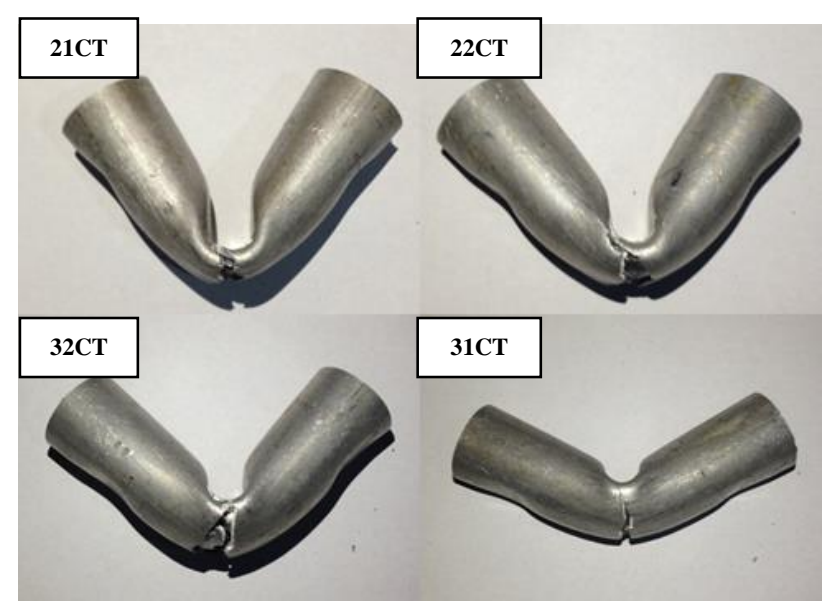

Fig. 5 The deformation of srtuctures under three bending point (front view)

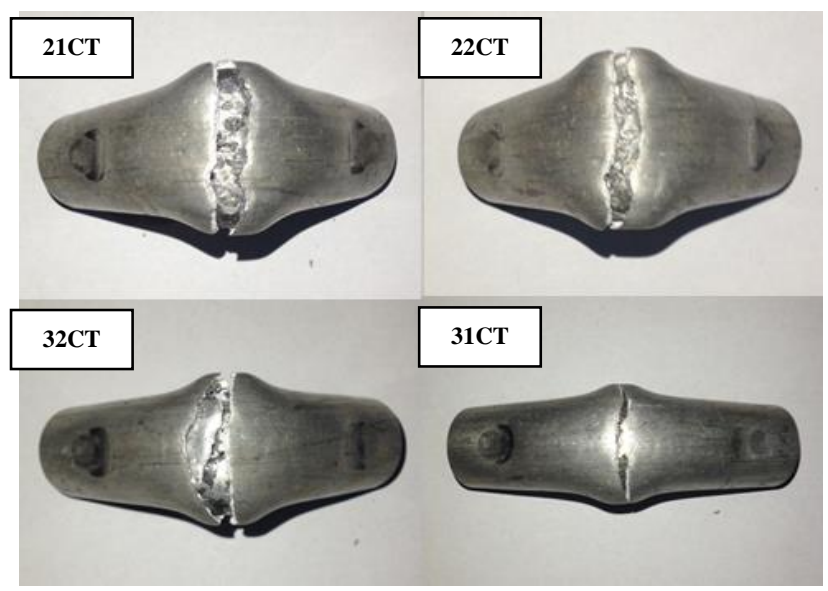

Fig. 6 The deformation of srtuctures under three bending point (bottom view)

\section{B. Energy absorption}

The failed area below the load-displacement curve represents the total energy absorption $E_{t}$.

$E_{t}=\int_{0}^{\delta_{\max }} F d \delta$

It also denoted the load of the punch, maximal displacement and displacement of the punch. As no failure points were noted in the response of the empty tubes, an upper limit was set for Eq. (1), which indicated the displacement value if the bending resulted in a $50 \%$ decrease in the crushing force for the empty structures.

Fig. 7 presents the total energy absorption of the thin-walled structures that undergo bending. Bending led to a variation in the absorbed energies of different structures. Also, the absorbed energy of the half foamfilled tri circular tubes was seen to be the highest wherein it was the lowest in the case of the full foam-filled tri circular tubes. When the aluminium tubes were filled with foam, they absorbed lesser energy compared to the foam-filled two circular tubes, as noted by the results shown by the sample $21 \mathrm{CT}$ in comparison to the 
corresponding 22CT sample, after bending. This was due to the significant reduction in the maximal bending displacement. Hence, it was not beneficial to use the same cellular filling materials in the tubular structures for increasing the energy absorption by a bending collapse. The researcher needs to determine the failure behaviour the foam filled structure and the structure's crushing performance. The tri foam-filled tubes possess a unique configuration, wherein they can maintain a high bending resistance and dissipate a lot of energy as they delay the sectional collapse.

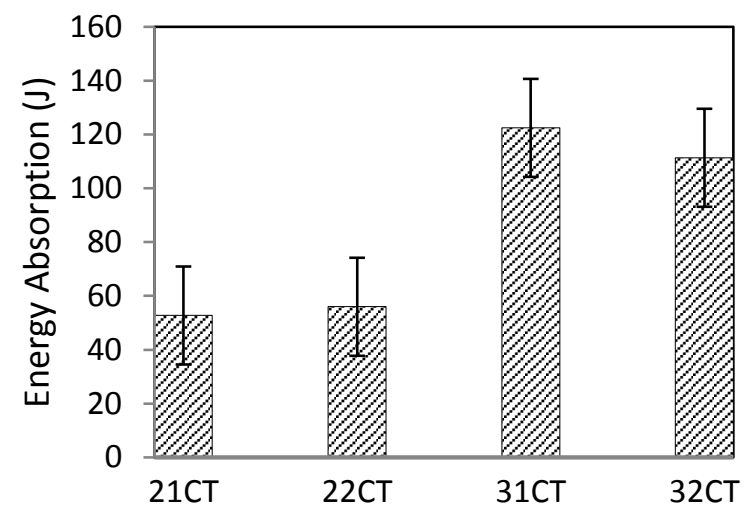

Fig. 7. Energy absorption of structures

\section{Specific Energy absorption}

Specific energy absorption indicates the energy absorption of the crushed sample mass per unit, and was defined as:

$$
S E A=E_{t} / m
$$

Table 2 Showed that the total mass of the foam-filled single and double tubes was similar.

Table 2. Experiment results

\begin{tabular}{ccccc}
\hline Tubes & $\begin{array}{c}\delta_{\max } \\
(\mathrm{mm})\end{array}$ & $\mathrm{E}_{\mathrm{t}}(\mathrm{J})$ & $\mathrm{m}(\mathrm{g})$ & $\begin{array}{c}\mathrm{SEA} \\
(\mathrm{J} / \mathrm{g})\end{array}$ \\
\hline $21 \mathrm{CTa}$ & 22.75 & 52.72 & 59.47 & 0.88 \\
$21 \mathrm{CTb}$ & 22.81 & 52.72 & 59.47 & 0.88 \\
$21 \mathrm{CTc}$ & 22.76 & 52.72 & 59.47 & 0.88 \\
$22 \mathrm{CTa}$ & 22.82 & 55.98 & 60.53 & 0.93 \\
$22 \mathrm{CTb}$ & 22.82 & 55.96 & 60.53 & 0.93 \\
$22 \mathrm{CTc}$ & 22.83 & 55.98 & 60.53 & 0.93 \\
$31 \mathrm{CTa}$ & 31.75 & 122.45 & 111.65 & 1.09 \\
$31 \mathrm{CTb}$ & 31.76 & 122.48 & 111.65 & 1.09 \\
$31 \mathrm{CTc}$ & 31.76 & 122.48 & 111.65 & 1.09 \\
$32 \mathrm{CTa}$ & 31.82 & 111.36 & 106.12 & 1.04 \\
$32 \mathrm{CTb}$ & 31.83 & 111.36 & 106.12 & 1.04 \\
$32 \mathrm{CTc}$ & 31.85 & 111.36 & 106.12 & 1.04 \\
\hline
\end{tabular}

Fig. 8 presents the comparison of the SEA of the 4 structure types. In comparison to the square tubes, the circular tubes absorbed more energy by axial crushing. The figure also showed that a majority of the energy was absorbed by the foam-filled tri tubes after the bending collapse per unit mass. Furthermore, the results indicated that the foam-filled double circular tubular structures of $53.8 \mathrm{~J}$ showed low energy absorption efficiency in comparison to the corresponding tri tubes of $117.4 \mathrm{~J}$, which was similar to the earlier results. This was because the foam-filled structures are not very compressible and also the foam-filled double-walled structures possessed smaller stroke efficiency than tri tubes. Table 2 showed that the SEA gain increased by $30 \%$ and by $70 \%$ during the bending collapse if the inner tube was used as the replacement for the foam filled circular tubes. The research must optimise the various parameters of these foam-filled tri tubes for obtaining the weight-efficient energy.

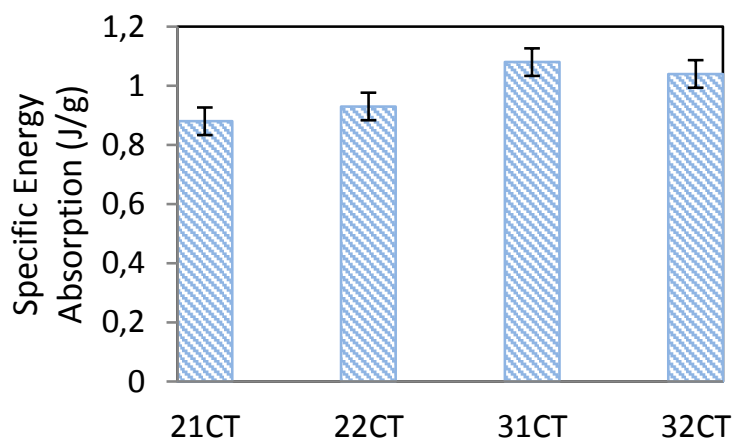

Fig. 8 Specific energy absorption of structures

\section{Energy-absorbing effectiveness}

Numerous studies were carried out to determine the efficiency of the novel structures and new materials by evaluating the energy-absorption effectiveness factor [30]. However, in this research, the samples were constrained and manufactured using similar material. Furthermore, a dimensionless energy absorption factor was used to compare the energy-absorbing structures with numerous combinations. This research described the energy-absorption effectiveness factor as the total energy quotient absorbed by the system to its maximal failure energy on the normal tensile. This process was manufactured using similar material volume, as follows:

$\psi=\frac{E_{t}}{\left(\sigma_{e} A_{e}+\sigma_{i} A_{i}+\sigma_{p l} A_{f}\right) L \varepsilon_{r}}$

Where; $\varepsilon_{r}$ denotes a uniaxial tensile engineering rupture strain on the tubes, $\sigma_{p l}$ is a plateau stress of the foam, $A_{f}$ denotes the cross-sectional area of the foam, while $\sigma_{e}$ and $\sigma_{i}$ represents the static flow stresses of the materials used for the external and internal tubes. Finally, $A_{e}$ and $A_{i}$ denote the cross-sectional area of the external and the internal tubes.

This study used Eq (3) and determined the values of the foam-filled single, double and empty tubes were subjected to the three-point bending, as shown in Fig. 9. The energy-absorbing effectiveness factor of the circular structures is higher than the square structures 
when subjected to axial crushing. In addition, the foamfilled tri circular tubes showed a higher energy absorbing effectiveness factor than the two circular tubes.

Results showed that when the tubes were subjected to the three-point bending collapse, the foamfilled tri circular tubes displayed the highest values. However, the foam-filled tri circular tubes showed a significant low value compared to the corresponding two circular tubes. In the case of the foam-filled multi-walled tubes, with a similar type of outer wall, there was a significant increase in the bending resistance if the foam filling was replaced by the inner tubes, for the two and tri-circular tubes. Hence, with regards to the energyabsorbing effectiveness factors noted for the bendingcrushing scenarios, it is better to use a foam-filled tri tubular structure in order to acquire a high energyabsorbing efficiency and a better bending resistance.

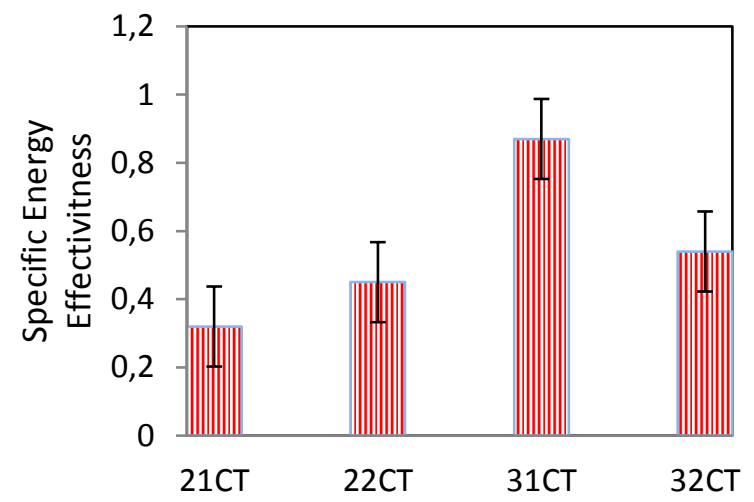

Fig. 9 Specific energy effectiveness of structures

\section{CONCLUSIONS}

In this study, the researchers carried out a three-point bending test for evaluating the bending crashworthiness of the thin-walled empty tubes and the foam-filled tubes. They investigated 4 types of foam-filled multi-walled circular tubes. They also determined and compared the energy absorption efficiency, load-deformation characteristics, and failure modes of the structures. They noted that the inner tube insertions and the foam fillers helped the tubular structures develop more plastic hinge lines, which increased the bending crush resistance. Numerous parameters related to the crashworthiness such as the SEA, energy-absorbing effectiveness and total energy absorption were examined in this study. Furthermore, higher resistance and better energy dissipation were noted by prolonging the sectional collapse. The foam-filled tri tubes absorbed maximal energy, collapse in accordance with each unit mass. The results indicated that when the tubes were subjected to the crushing an bending activities, the foam-filled tri circular tubes showed a higher energy-absorbing effectiveness compared to the foam-filled two circular tubes. Therefore, in conclusion, the foam-filled tri tubular (1.09 J/g) structure illustrated a better bending crashworthy performance than the two-tube structure
$(0.93 \mathrm{~J} / \mathrm{g})$. Hence, the researchers recommended the use of foam-filled tri tubular structures as better and crashworthy structural components in the field of vehicle engineering as they possessed a higher energy-absorbing efficiency and better bending resistance.

\section{REFERENCES}

[1] Lu G and Yu TX.Energy absorption of structures and materials. Cambridge: Woodhead Publishing Ld., 2003.

[2] Najibi, A., Ghazifard, P. \& Alizadeh, P. 2020. Numerical crashworthiness analysis of a novel functionally graded foam-filled tube. Journal of Sandwich Structures \& Materials, 1099636219900334.

[3] Li, Z., Rakheja, S. \& Shangguan, W.-B. 2019. Study on crushing behaviors of foam-filled thin-walled square tubes with different types and number of initiators under multiple angle loads. Thin-Walled Structures, 145, 106376.

[4] Zhang Y, Sun G, Li G, et al. Optimization of foamfilled bitubal structures for crashworthiness criteria.Mater Des 2012; 38: 99-109.

[5] Marzbanrad J and Keshavarzi A. A Numerical and experimental study on the crash behavior of the extruded aluminum box with elastic support. Latin Am J Solid Struct2014; 11: 1329-1348.

[6] Abramowicz W. Thin-walled structures as impact energy absorbers. Thin-Wall Struct 2003; 41: 91-107.

[7] Kallina I, Zeidler F, Baumann K, et al. The offset crash against a deformable barrier, a more realistic frontal impact. In: Proceedings to the 14th international technical conference on enhanced safety of vehicles, Munich, Germany, 23 May-27 May 1994, pp.1300-1304.

[8] Chen W. Experimental and numerical study on bending collapse of aluminum foam-filled hat profiles.Int J Solid Struct2001; 38: 7919-7944.

[9] Kecman D. Bending collapse of rectangular and square section tubes.Int J Mech Sci1983; 25: 623636.

[10] Poonaya S, Teeboonma U and Thinvongpituk C. Plastic collapse analysis of thin-walled circular tubes subjected to bending.Thin-Wall Struct2009; 47: 637645.

[11] Hilditch T, Atwell D, Easton M, et al. Performance of wrought aluminium and magnesium alloy tubes in threepoint bending.Mater Des2009; 30: 2316-2322.

[12] Seitzberger M, Rammerstorfer FG, Gradinger R, et al. Experimental studies on the quasi-static axial crushing of steel columns filled with aluminium foam. Int J Solid Struct2000; 37: 4125-4147.

[13] Yuen SCK, Nurick GN and Starke RA. The energy absorption characteristics of double-cell tubular profiles. Latin Am J Solid Struct2008; 5: 289-317.

[14] Zhang X and Cheng G. A comparative study of energy absorption characteristics of foam-filled and multi-cell square columns.Int J Impact Eng2007; 34: 1739-1752. 
[15] Kashani MH, Alavijeh HS, Akbarshahi H, et al. Bitubular square tubes with different arrangements under quasi-static axial compression loading.Mater Des 2013; 51: 1095-10103.

[16] Guo LW, Yu JL and Li ZB. Experimental studies on the quasi-static bending behavior of double square tubes filled with aluminum foam. Acta Mech 2010; 213: 349-358.

[17] Guo LW and Yu JL. Dynamic bending response of double cylindrical tubes filled with aluminum foam.Int J Impact Eng 2011; 38: 85-94.

[18] Guo LW and Yu JL. Bending behavior of aluminum foam-filled double cylindrical tubes. Acta Mech2011; 222: 233-244.

[19] Djamaluddin, F., Abdullah, S., Ariffin, A.K. and Nopiah, Z.M. (2015a) 'Multi objective optimization of foam-filled tubular circular tubes for quasi-static and dynamic responses',Latin American Journal of Solids and Structures, Vol. 12, pp.1126-1143.

[20] Djamaluddin, F., (2019) 'Review deformation and optimisation crashworthiness method for foam filled structures' Latin American Journal of Solids and Structures 16 (7)

[21] Djamaluddin, F., Abdullah, S., Ariffin, A.K. and Nopiah, Z.M. (2019) 'Optimisation and validation of full and half foam filled double circular tube under multiple load cases, International Journal of Crashworthiness 24 (4), 389-398.

[22] Djamaluddin, F., Abdullah, S., Arrifin A.K. and Nopiah Z.M. (2018) 'Crush analysis of the foamfilled bitubal circular tube under oblique impact' IOP Conf. Series: Materials Science and Engineering 308.

[23] Vesenjak, M., Duarte, I., Baumeister, J., et al. 2020. Bending performance evaluation of aluminium alloy tubes filled with different cellular metal cores. Composite Structures, 234, 111748.

[24] Li ZB, Yu JL, Zheng ZJ, et al. An experimental study on the crashworthiness of thin-walled tubes and their metallic foam-filled structures. J Experiment Mech2012; 27: 77-86.

[25] Li ZB, Yu JL and Guo LW. Deformation and energy absorption of aluminum foam-filled tubes subjected to oblique loading.Int J Mech Sci2012; 54: 48-56.

[26] Li ZB, Zheng ZJ, Yu JL, et al. Crashworthiness of foamfilled thin-walled circular tubes under dynamic bending. Mater Des2013; 52: 1058-1064.

[27] Kim HS and Wierzbicki T. Effect of the crosssectional shape of hat-type cross-sections on crash resistance of an ' $S$ ''-frame. Thin-Wall Struct2001; 39: 535-554.

[28] Velmurugan R and Muralikannan R. Energy absorption characteristics of annealed steel tubes of various cross sections in static and dynamic loading. Latin Am J Solid Struct2009; 6: 385-412.

[29] GB/T 228.1-2010.Metallic materials - tensile testing -Part 1: Method of test at room temperature. Beijing: Chinese Standard Press, 2010.
[30]Norman J. Energy-absorbing effectiveness factor.Int J Impact Eng2010; 37: 754-765.

Creative Commons Attribution License 4.0 (Attribution 4.0 International, CC BY 4.0)

This article is published under the terms of the Creative Commons Attribution License 4.0

https://creativecommons.org/licenses/by/4.0/deed.en_US 